\title{
DNA-based photoacoustic nanosensor for interferon gamma detection
}

Jennifer Morales, ${ }^{\dagger,}, \#$ Robert H. Pawle, ${ }^{\ddagger}, \#$ Namik Akkilic, $§$ Yi Luo, ${ }^{\S}$ Marvin Xavierselvan, ${ }^{\prime}$ Rayan Albokhari, ${ }^{\|}$Isen Andrew C. Calderon, ${ }^{\dagger}$ Scott Selfridge, ${ }^{\dagger}$ Richard Minns, ${ }^{\dagger}$ Larry Takiff, ${ }^{\ddagger}$ Srivalleesha Mallidi, $\|$ and Heather A. Clark*,†,

${ }^{\dagger}$ Department of Bioengineering, Northeastern University, Boston, MA 02115, USA, ${ }^{\ddagger}$ Akita Innovations LLC, Billerica, MA 01862, USA, §Department of Pharmaceutical Sciences, Northeastern University, Boston, MA 02115, USA, "Wellman Center for Photomedicine, Massachusetts General Hospital, Harvard Medical School, Boston, MA 02114, USA, ${ }^{\perp}$ Department of Chemistry and Chemical Biology, Northeastern University, Boston, MA 02115, USA

\# These authors contributed equally to this work

*Corresponding author:

Heather A. Clark

Department of Bioengineering \& Department of Chemistry and Chemical Biology Northeastern University

360 Huntington Avenue, Boston, MA 02115

617-373-3091

H.clark@northeastern.edu 


\section{Experimental Section}

\section{Materials}

All DNA sequences and modified nucleotides were commercially synthesized by Gene Link (Hawthorne, NY). The following proteins were commercially obtained for this project: recombinant human interferon gamma receptor 2 (IFN $\gamma \mathrm{R} 2$, Ray Biotech, Norcross, GA), recombinant human interferon gamma receptor 1 (IFN $\gamma R 1$, Novoprotein, Summit, NJ), recombinant human interferon gamma cytokine (IFN $\gamma$, Sigma Aldrich, St. Louis, MO), and recombinant human interleukin-18 cytokine (IL-18, Gibco, ThermoFisher, Waltham, MA). Surface plasmon resonance sensor chips were obtained from Nicoya Lifesciences (Kitchener, Canada). Polyethylene tubing (BTPE-50) was obtained from Instech Laboratories (Plymouth Meeting, PA). All chemicals listed were purchased from Sigma Aldrich (St. Louis, MO).

\section{Dye synthesis}

Synthesis scheme and methods are detailed in the supporting information. All synthetic transformations were performed under an argon atmosphere with magnetic stirring unless otherwise mentioned. Flash chromatography was performed using a CombiFlash with RediSep pre-packed silica columns (230-400 mesh) as the stationary phase unless otherwise noted. NMR spectra were acquired on a Varian $400 \mathrm{MHz}$ Unity Inova spectrometer. Chemical shifts are reported relative to residual protonated solvent (7.26 ppm for $\mathrm{CHCl}_{3}$ ). All reactants and solvents were purchased from commercial suppliers and used without further purification unless otherwise noted. Electronic absorbance spectra were acquired with a Cary 50Scan UV-Visible spectrophotometer.

\section{Phthalocyanine-DNA Conjugation}

We accomplished conjugation to the DNA through the amino group axially attached to the central silicon. The approach is shown in SI Figure 10. We prepared the DNA sequence on a solid support following standard processes, with one nucleoside on the DNA containing an NHS ester group. Pc-1 was conjugated to the DNA through displacing the NHS ester group with the amine group on Pc-1. After the conjugation, the solid support was cleaved by conventional methods.

\section{DNA sequence generation}

DNA sequences were designed to assemble with predictable secondary structure and generated as previously described. ${ }^{1}$ Briefly, DNA sequences were generated in-house using the following computational methods: the secondary structure of each sequence was assessed using RNAfold (nucleic acid structure prediction software) with minimum energy calculations for determining DNA self-assembly. Stability and annealing of each structure was analyzed by RNAfold ${ }^{2}$ minimum free energy calculations and thermodynamic ensemble predictions. Then, they were computationally assessed by model.it ${ }^{3}$ to confirm their $3 \mathrm{D}$ tertiary structure. To create 3D rendering, sequences of the nanosensor macromolecular structure were processed in Protein Data Bank files by McFold $^{4}$ and visualized with Visual Molecular Dynamics software. ${ }^{5}$

\section{Receptor-DNA attachment}

The receptor-DNA conjugates were prepared by polyhistidine-nitrilotriacetic acid (NTA) binding chemistry using procedures by Shimada et al. ${ }^{6}$ IFN $\gamma$ recombinant receptors were purchased with polyhistidine tags intact and NTA-DNA was obtained from Genelink. The receptors have different attachment sites on the sensor with the following sequences: IFN $\gamma \mathrm{R} 1$ sequence (5'ATGGTGA(S-C6-dT-NTA)GCGTG-3') and IFN $\gamma$ R2 sequence (5'ATCGC(S-C6-dT-NTA)GAATTAT-3'). First, the NTA was charged with $\mathrm{Ni}^{2+}$ : NTA-tagged DNA in Tris Buffered Saline (TBS, $25 \mathrm{mM}$ Tris hydrochloride, $137 \mathrm{mM}$ sodium chloride, 2.68 $\mathrm{mM}$ potassium chloride, $\mathrm{pH}$ 7.4) was mixed with equimolar concentrations of nickel(II) chloride in $100 \mathrm{mM}$ MOPS buffer (3( $\mathrm{N}$-morpholino) propanesulfonic acid, $\mathrm{pH} 7.9)$ at room temperature $\left(23^{\circ} \mathrm{C}\right)$ for $30 \mathrm{~min}$. Next, the $\mathrm{Ni}^{2+}$-charged NTA-DNA was dissolved in PBS and mixed with equimolar polyhistide-tagged receptor (final concentration of $25 \mathrm{nM}$ ) at room temperature for 30 min and concentrated by ultracentrifugation three times using $3 \mathrm{kDa}$ Amicron centrifuge filters (Millipore) in PBS $\mathrm{pH}$ 7.4. The filtered receptor-NTA-DNA solutions were collected and stored at $4{ }^{\circ} \mathrm{C}$ for sensor assembly.

\section{Sensor assembly}


The nanosensors were prepared in two steps: assembly of the DNA scaffold and receptor attachment. DNA annealing steps were based on the procedures by Zhou et al. ${ }^{7}$ where all DNA sequences for the sensor (except receptor-NTA-DNA sequences) were dissolved in PBS pH 7.4, heated to $90^{\circ} \mathrm{C}$ in a heat block for ten minutes, then the heat block was turned off and the sensors left to cool to room temperature over $4 \mathrm{~h}$. Next, the receptor-NTA-DNA sequences were added to the nanosensor solution, incubated for $1 \mathrm{~h}$, and then filtered three times to remove unattached receptors with $100 \mathrm{kDa}$ Amicron centrifuge filters (Millipore) and PBS $\mathrm{pH}$ 7.4. The filtered nanosensor solution was collected and stored at $4{ }^{\circ} \mathrm{C}$. Polyacrylamide gel electrophoresis was run on the sensors to determine the assembly of the full sensor (SI Figure 2). Sensors were run in 20\% Tris-borate-EDTA gels (Invitrogen) in $0.5 \mathrm{X}$ Tris-borate-EDTA buffer according to Invitrogen instructions at $70 \mathrm{~V}, 10 \mathrm{~mA}$ over ice for $4 \mathrm{~h}$.

\section{Transmission electron microscopy}

DNA nanosensors were imaged on a Tecnai F20 by negative staining and in cryo-preparations. All grids were glow discharged for $30 \mathrm{~s}$ with a HDT-400 Hydrophilic Treatment Device (Jeol Datum). Negatively stained samples were prepared using the single droplet method ${ }^{8}$ on Carbon coated, 300 mesh copper TEM grids (Electron Microscopy Sciences) and imaged at $200 \mathrm{eV}$. Frozen hydrated samples for cryo-TEM were prepared on C-flat Holey Carbon grids (Electron Microscopy Sciences) with a Cyroplunge 3 GentleBlot System (Gatan) following Gatan procedures with a $3 \mathrm{~s}$ blot. All TEM images were adjusted for contrast with Gatan Microscopy Suite 3 Software (Gatan).

\section{SPR methods and analysis}

The affinity of the receptors and sensors was determined by localized surface plasmon resonance using an OpenSPR (Nicoya, Kitchener, Canada). We used this instrument to monitor the kinetic interactions of cytokine binding to sensors on the SPR chip surface. This results in changes in refractive index shift that shift the absorbance peak of the chips by picometers. All experiments followed Nicoya's OpenSPR protocols. Briefly, biotin-tagged sensors were immobilized to a streptavidin-coated chip by streptavidin-biotin binding over a $10 \mathrm{~min}$ incubation period. HEPES buffered saline (HBS) (50 mM HEPES pH 7.4, $140 \mathrm{mM}$ sodium chloride, $1.5 \mathrm{mM}$ sodium phosphate, $0.005 \%$ Tween 20 ) was the primary buffer used for all processes, including sample preparation and running buffer. Next, two injections of $80 \%$ isopropanol $(\sim 5 \mu \mathrm{L})$ and one injection of bovine serum albumin $(200 \mu \mathrm{L}, 1$ $\mathrm{mg} / \mathrm{mL}$ in HBS) were passed over the surface of the chip for bubble prevention and to reduce non-specific binding, respectively. Then, injections containing samples were passed over the chip's surface at $20 \mu \mathrm{L} / \mathrm{min}$ for $5 \mathrm{~min}$. All data analysis followed OpenSPR recommended procedures for evaluation fit models (1:1 and 1:2 binding) using Tracedrawer real-time kinetic analysis software (Ridgeview Instruments, Vange, Sweden).

\section{Quantum yield determination}

The quantum yield of Pc-1 was determined with indocyanine green (ICG) as a standard according to procedures by Würth et al. ${ }^{9}$ Absorbance and fluorescence measurements were recorded in $40 \mu \mathrm{L}$ quartz cuvettes on a Spectramax M3 Multi-mode plate reader (Molecular Devices) and Photomultiplier Detection System Model 814 (Photon Technology International), respectively. The quantum yield was calculated using a|e UV-Vis-IR Spectral Software version 2.2 (FluorTools).

\section{Sensors Fluorescence characterization}

Sensors were calibrated by standard additions of IFN $\gamma$. Sensors were placed in a $40 \mu \mathrm{L}$ quartz cuvette and absorbance of the sensor solutions before and after additions was recorded on a Spectramax M3 Multi-mode plate reader (Molecular Devices). Fluorescence measurements for each solution change were recorded over $500 \mathrm{~s}$ by a Photomultiplier Detection System Model 814 (Photon Technology International). Data collection, correction, and analysis were done by the standard addition method. ${ }^{10}$ Calibration curve, limit of detection, and dynamic range were generated using standard protocols as described by Borysiak et al. ${ }^{11}$

\section{Photoacoustic setup, experiment, and analysis}

Polyethylene tubes (BTPE-50) were filled with approximately $30 \mu \mathrm{L}$ of sample solutions, and the ends were sealed and placed in a custom-made mold to enable PA imaging. The tubes were then immersed in deionized water to perform PA imaging at multiple wavelengths $(680-950 \mathrm{~nm})$. A commercially available FUJIFILM VisualSonics Vevo LAZR system was used to image the tubes as previously demonstrated by Frenette et al. ${ }^{12}$ At every wavelength, an average of PA signal generated from 20 pulses was plotted. A $20 \mathrm{MHz}$ transducer was used to obtain the PA signal (LZ 250). The transducer, along with the fibers to deliver the light required for PA signal generation, were connected to a motor stage to facilitate 3D scanning of the tubes. Data processing of the absorbance 
and photoacoustic signals form the photoacoustic phantom experiments were normalized to the mean: $\Delta X / X=\left(X-X_{0}\right) / X_{0}$. Here $\Delta X / X$ is the change in signal relative to the mean, $X$ is the signal and $X_{0}$ is the mean signal value. ${ }^{13-14}$ 
Receptor sequence 1

Receptor sequence 2

Central intersection sequence 1

Central intersection sequence 2

Central intersection sequence 3

Central intersection sequence 4

Dye sequence 1

Dye sequence 2

Foundation sequence

\section{Sequence name}

$5^{\prime}-3^{\prime}$ DNA Sequence

ATGCMCATGCGTE

ATCGCTGAATTAT

GCGGAGCCGCATTAGCGAGTTCGGAATCG

GCTAATGCCCATCAACGAGTTCGGAATCG

GTTGATGGCTAAGGTCGAGTTCGGAATCG

GACCTTAGGGCTCCGCGAGTTCGGAATCG

ACCAGTGTGTTCGTGTCATCTAGGA

AACTTAATAAATAGGATGCGCGGG

ATAATTCAGCGATCCCCGCGCATCCTATTTATTAAGTT-TTTT-TCC

AGATGACACGAACACACTGGTCACGCATCACCATCGATTCCGAACTC

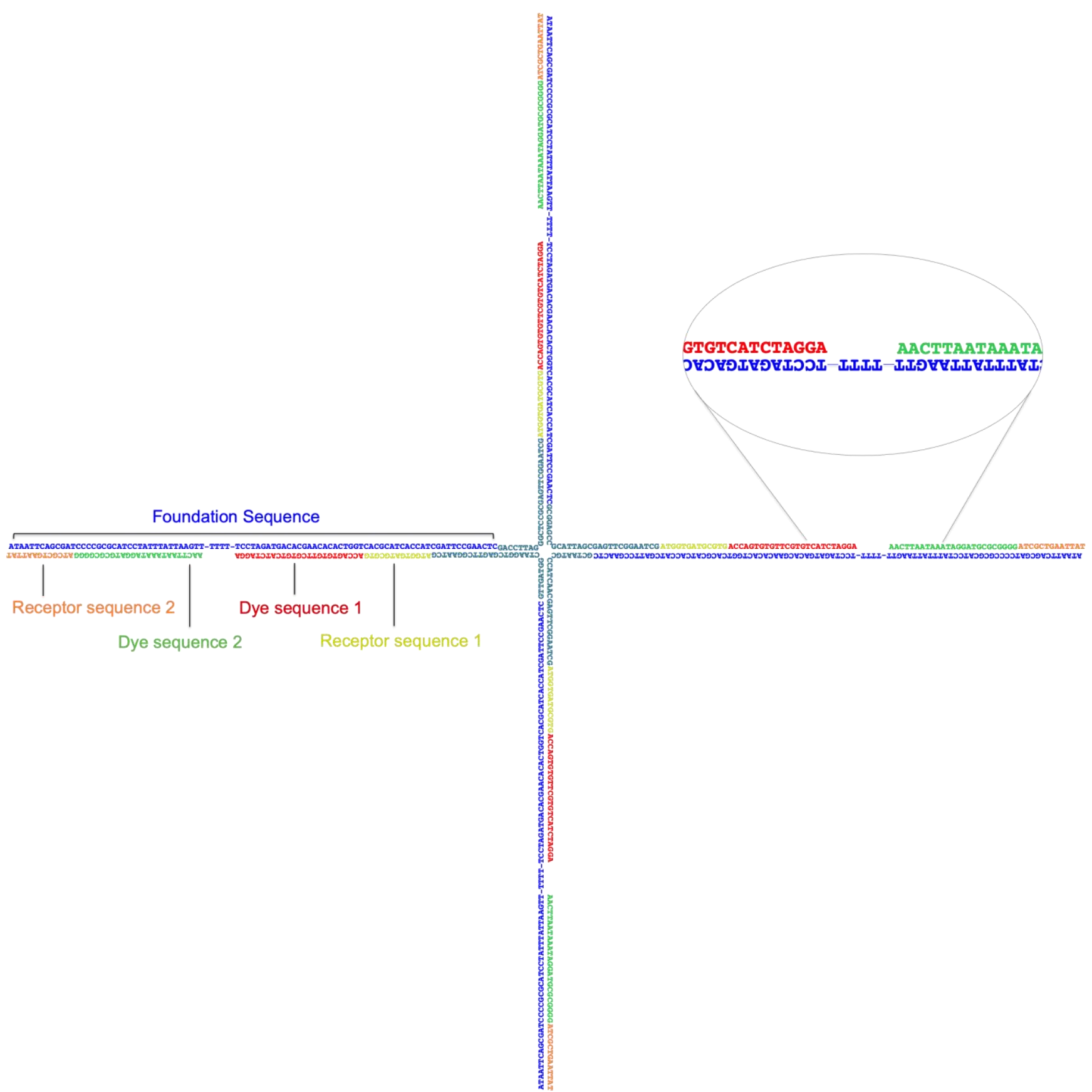

SI Figure 1. The sensors individual DNA sequences (top) and their position within the sensor assembly (bottom). 


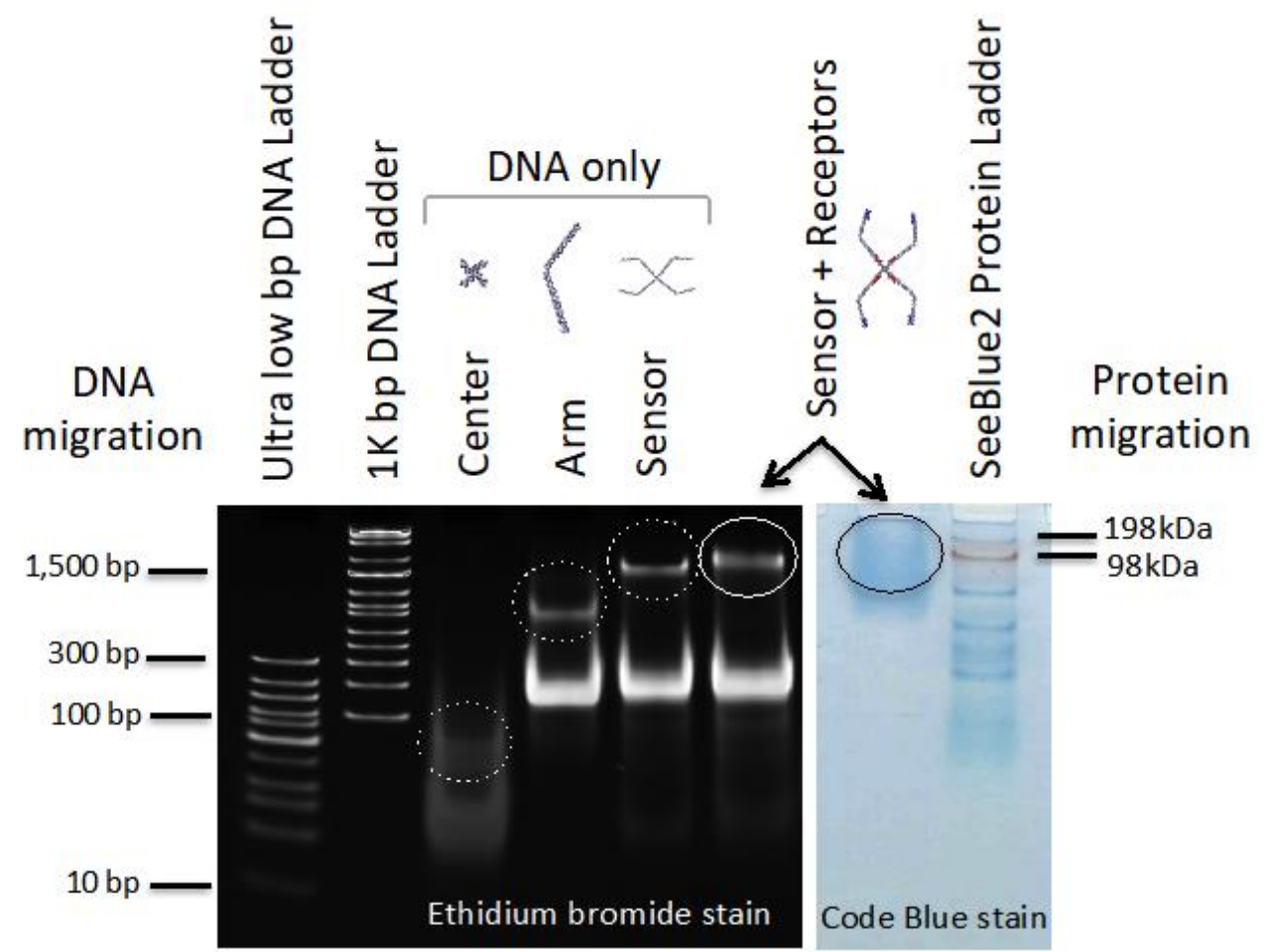

SI Figure 2. Gel electrophoresis of the sensor and associated components: 20\% Tris-Borate-EDTA (TBE) polyacrylamide gel electrophoresis in $0.5 \mathrm{X}$ TBE running buffer run at 70V, $10 \mathrm{mAmps}$ at room temperature for 1 hour. (Ethidium bromide stained PAGE gel lanes from left to right: Ultra low bp DNA ladder (ThermoFisher), Trackit $1 \mathrm{~K}$ base pair ladder (Invitrogen), central intersection, single sensor arm, full sensor structure without receptors, full sensor with associated receptors). Code blue safe protein stain (ThermoFisher) lanes from left to right: full sensor with associated receptors, SeeBlue2 protein ladder (Invitrogen). Gel bands in dotted circles denote the migration of DNA complexes through the gel. Gel bands in full circles denote the migration band of the same full sensor complex imaged in ethidium bromide and Code Blue protein stain. 
a
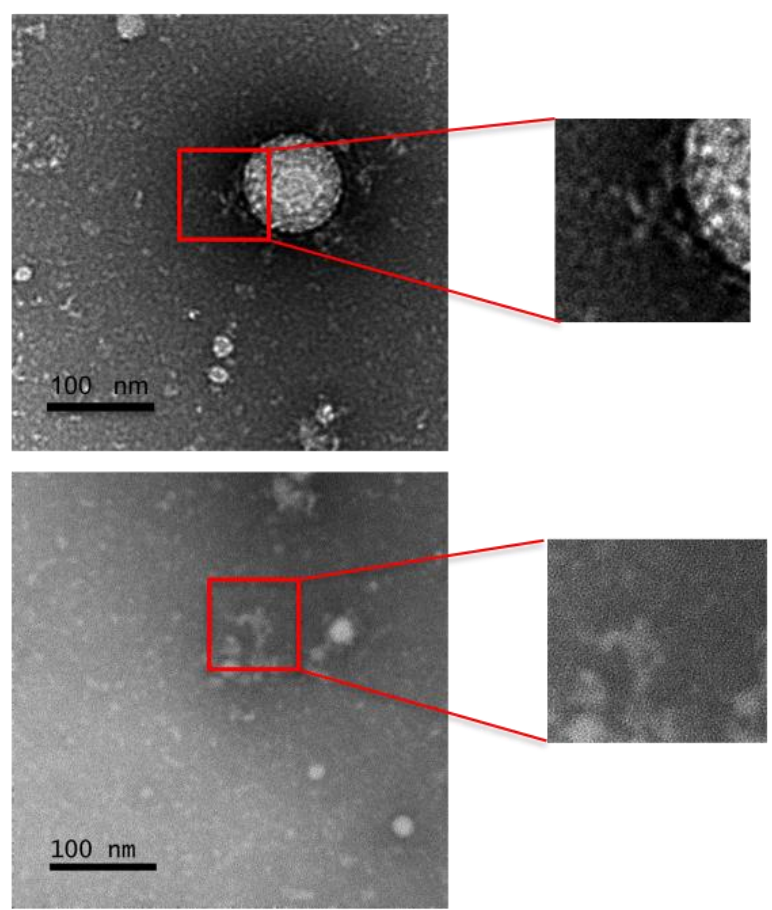

b
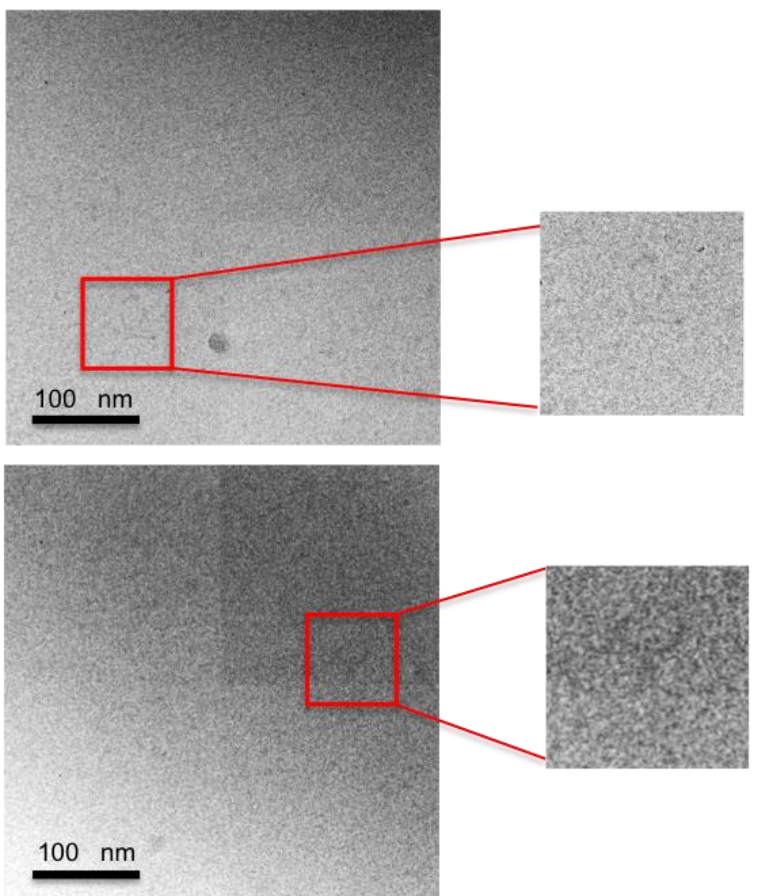

SI Figure 3: Transmission electron microscopy images of DNA nanosensors (red boxes) prepared by negative stained with $2 \%$ NanoW (a) and cryo-prepared (b). (Scale bar $=100 \mathrm{~nm})$ 


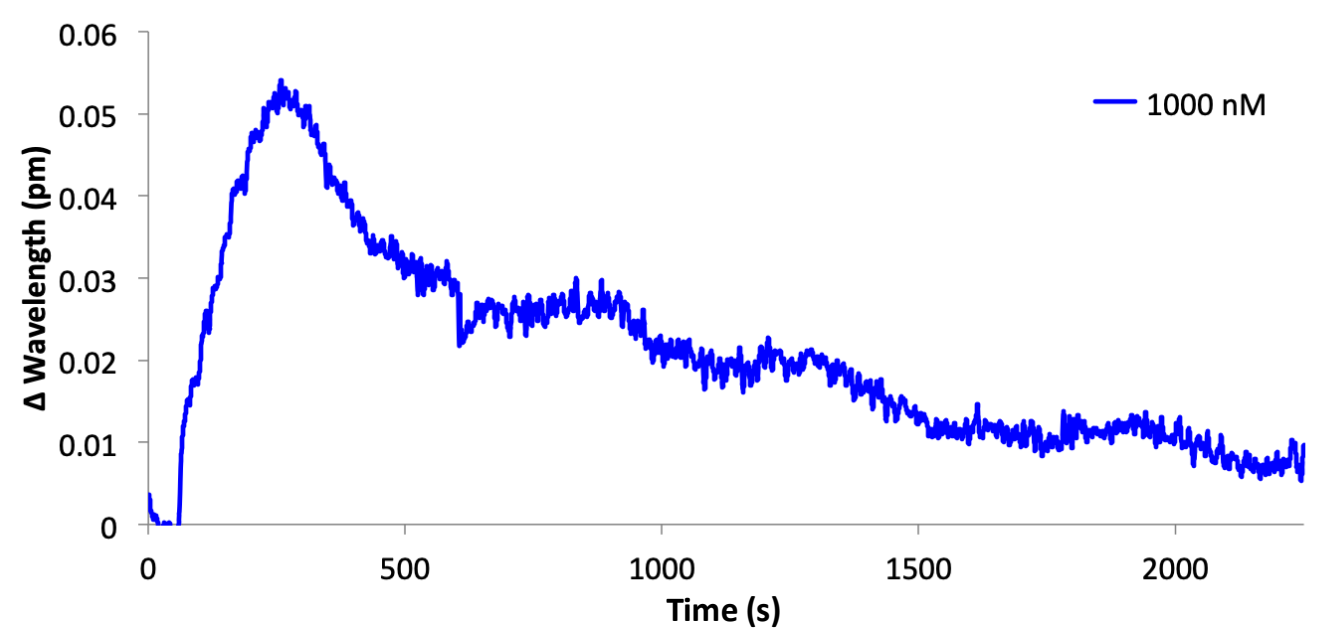

SI Figure 4. Complete sensogram for $1000 \mathrm{nM} \mathrm{IFN} \gamma$ binding to immobilized nanosensor. 
a

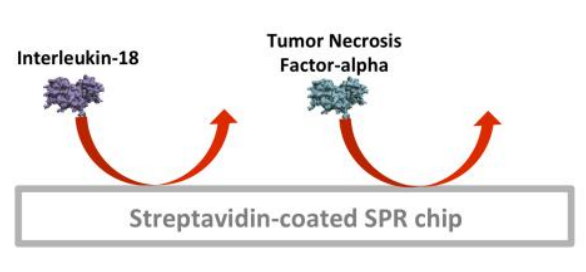

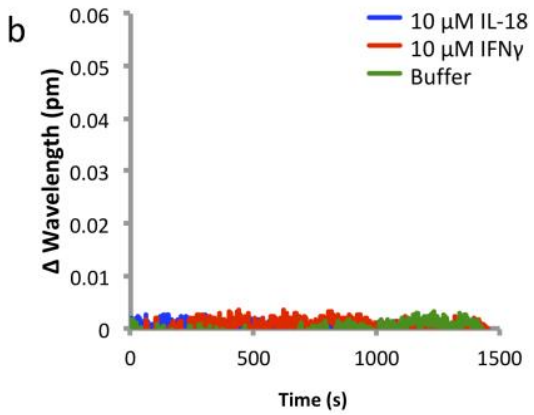

SI Figure 5. To determine if the SPR signal is biased by injections of analyte, we recorded the kinetics of $10 \mu \mathrm{M}$ of IFN $\gamma$ and IL-18 on a sensor-free SPR chip (a). No increases in signal were observed (b). 
a

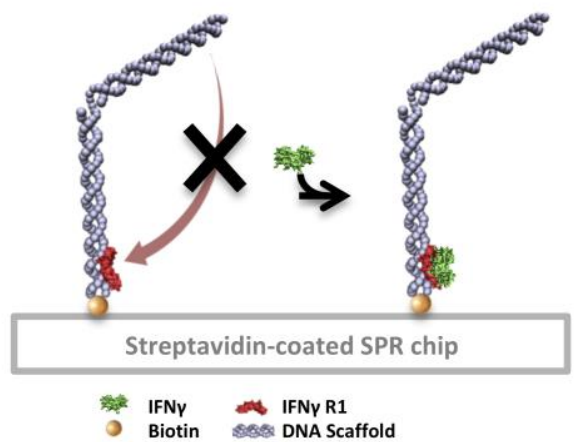

b

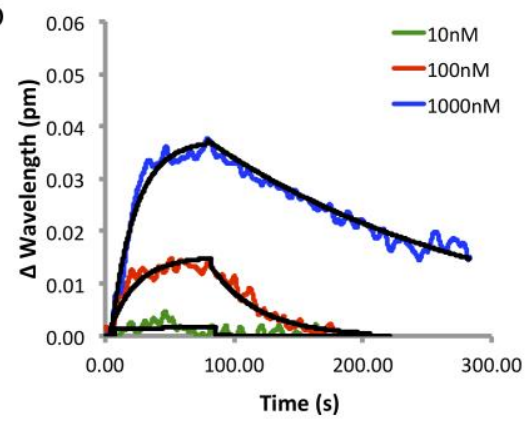

SI Figure 6. Single-arm sensors with only IFN $\gamma$ R1 were secured to a SPR chip using Biotin-Streptavidin binding (a). Kinetics of the sensors' response is 1:1 binding with a $K_{D}$ of $93.2 \mathrm{nM}(\mathrm{b})$. 

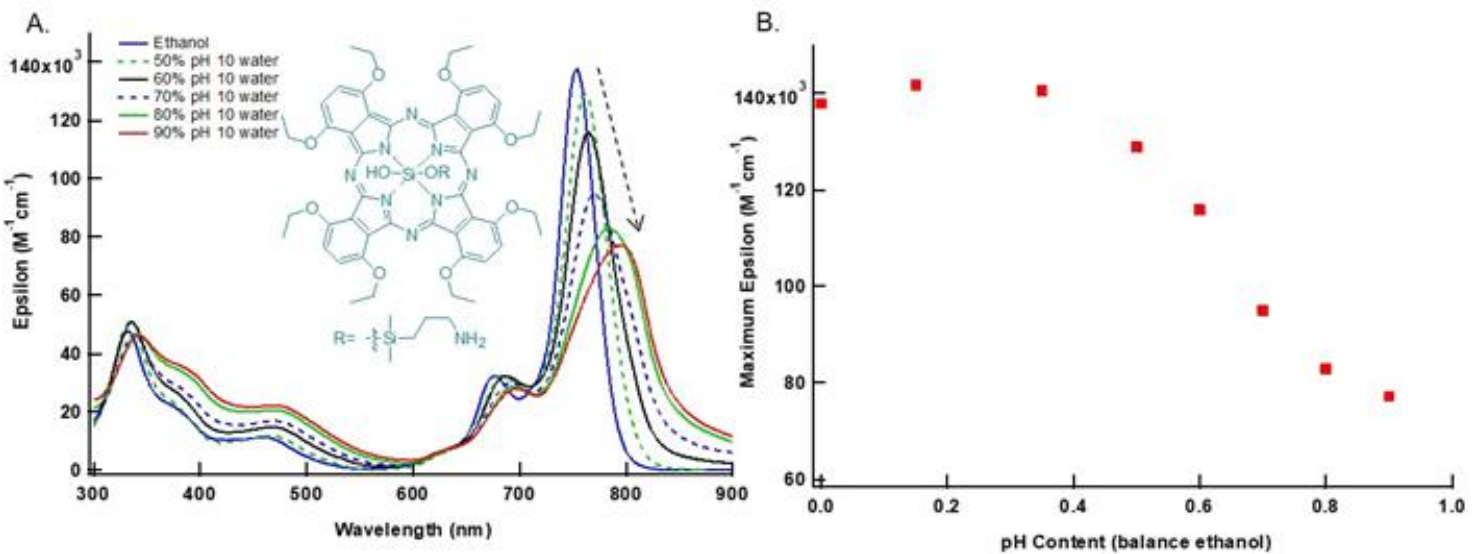

SI Figure 7. a) Absorbance spectra of 1 in ethanol:alkaline water solvent systems. b) Molar absorptivity with water content. 


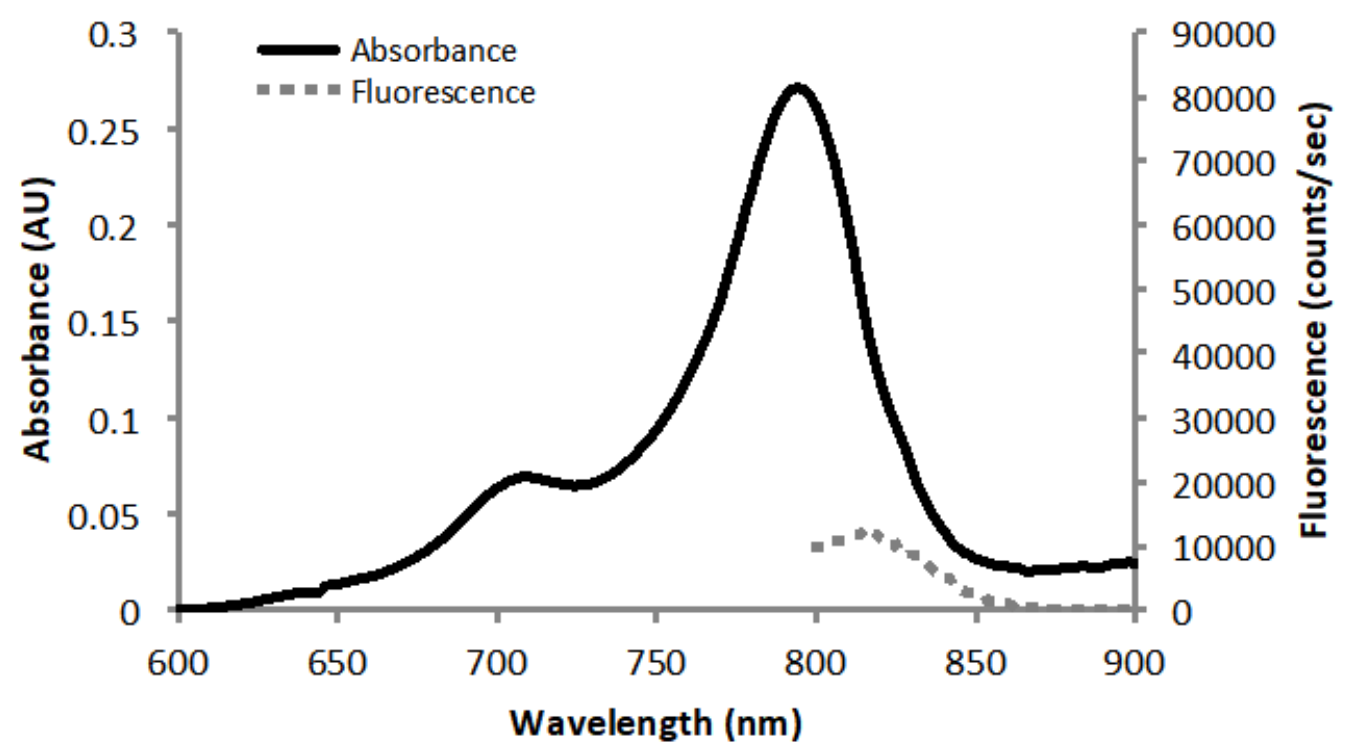

SI Figure 8. Quantum yield determination of Pc-1 $\left(\Phi_{\mathrm{f}}=0.0125\right)$ scaled to show approximate fluorescence yield. Indocyanine green used as a reference $\Phi_{\mathrm{f}}=0.027 .{ }^{15}$ 

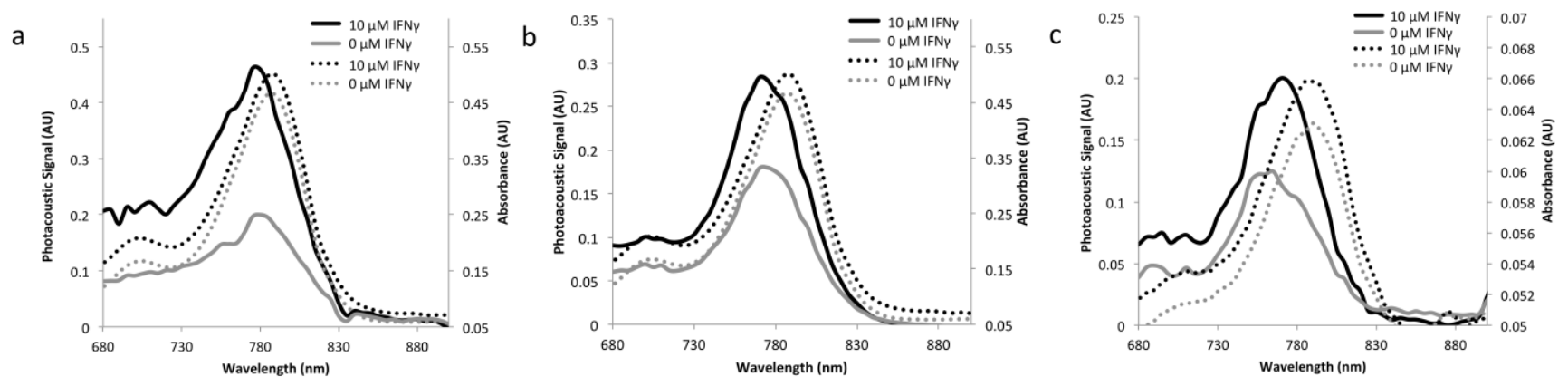

SI Figure 9. Photoacoustic (solid line) and absorbance (dotted line) spectra of the three independent trials a, b, and c in Figure 5. The photoacoustic spectra shown are the average of three regions of interest from each individual experiment. 

on solid support
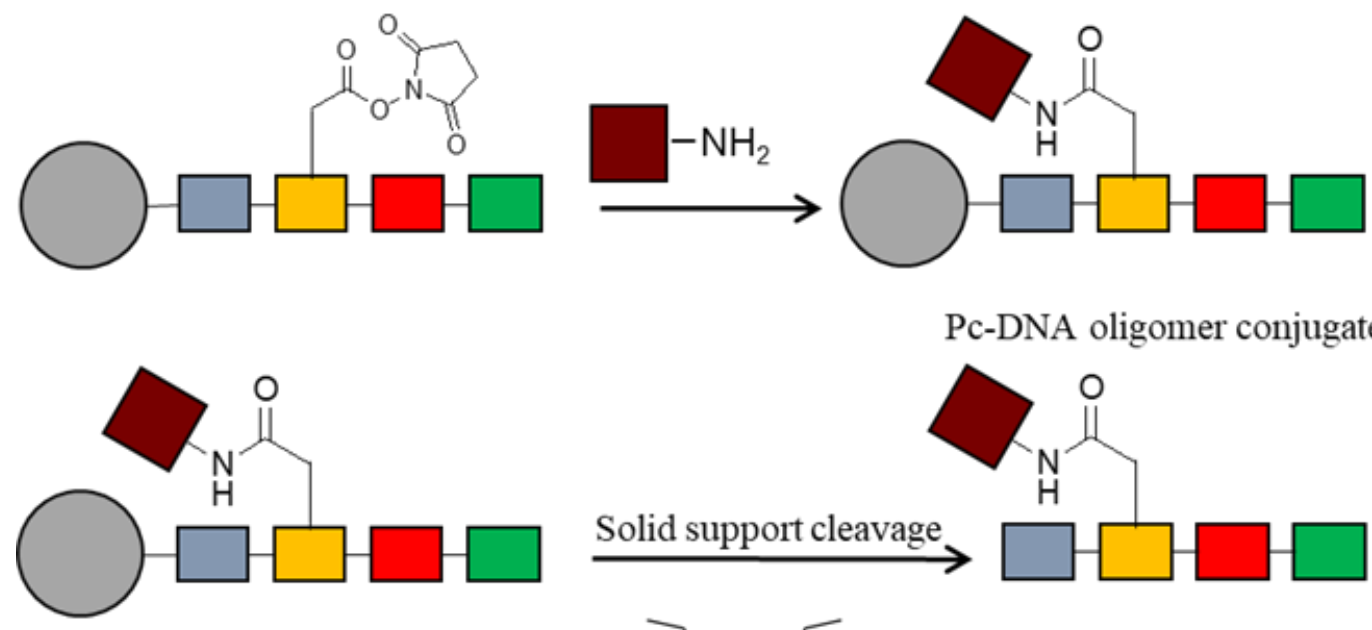

Pc-DNA oligomer conjugate

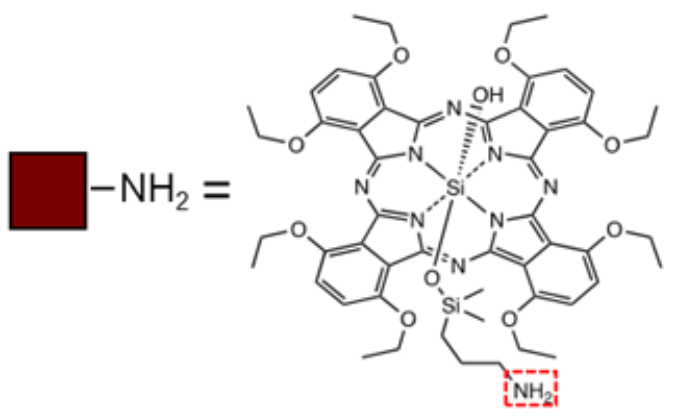

Pc with axial amino substituent

SI Figure 10. Pc-DNA conjugation process. 


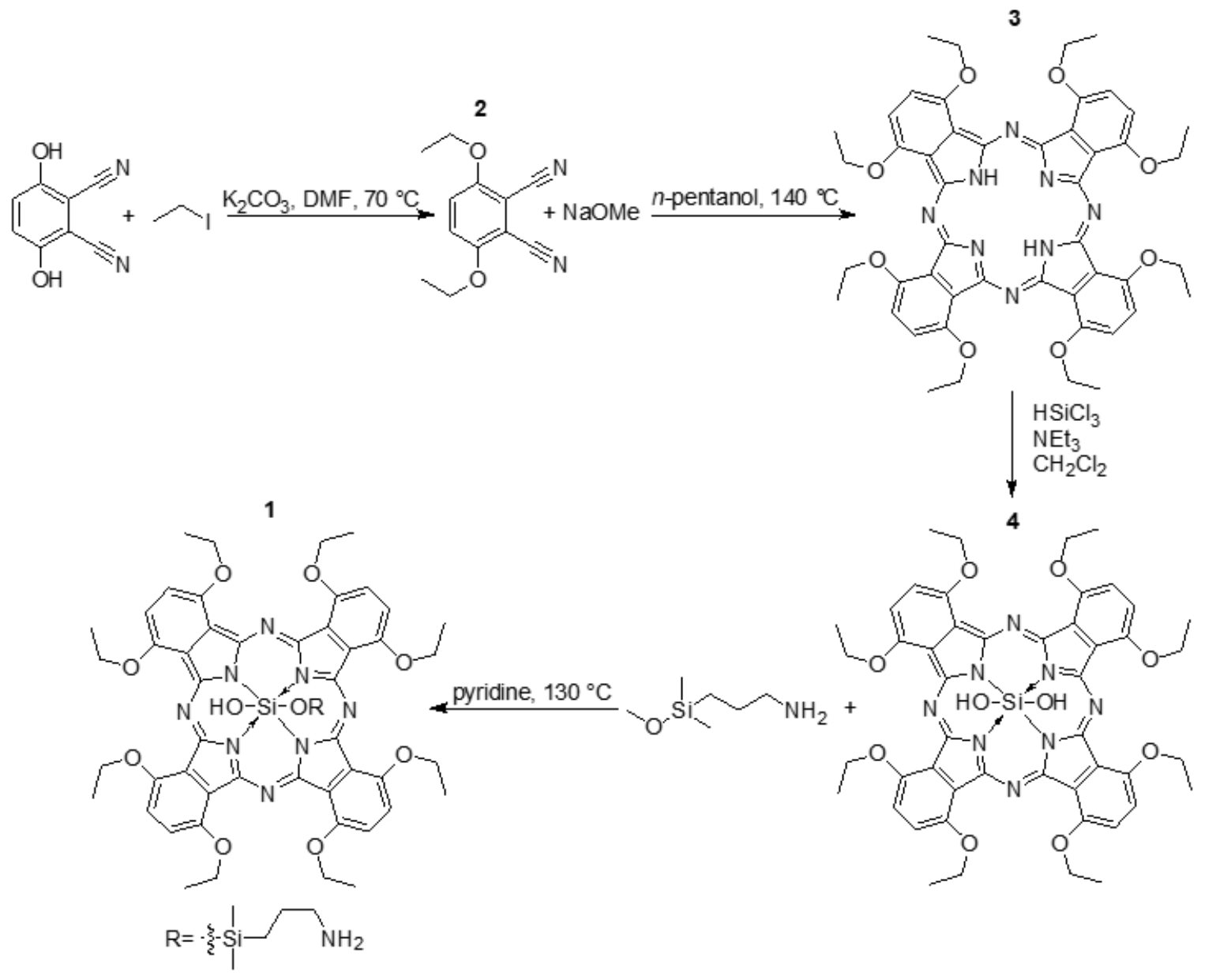

Scheme S-1. 3,6-Diethoxyphthalonitrile (2) was prepared according to published procedure. Melting point: 201-204 ${ }^{\circ} \mathrm{C}$ (literature $\left.203^{\circ} \mathrm{C}\right) .^{16}$ 


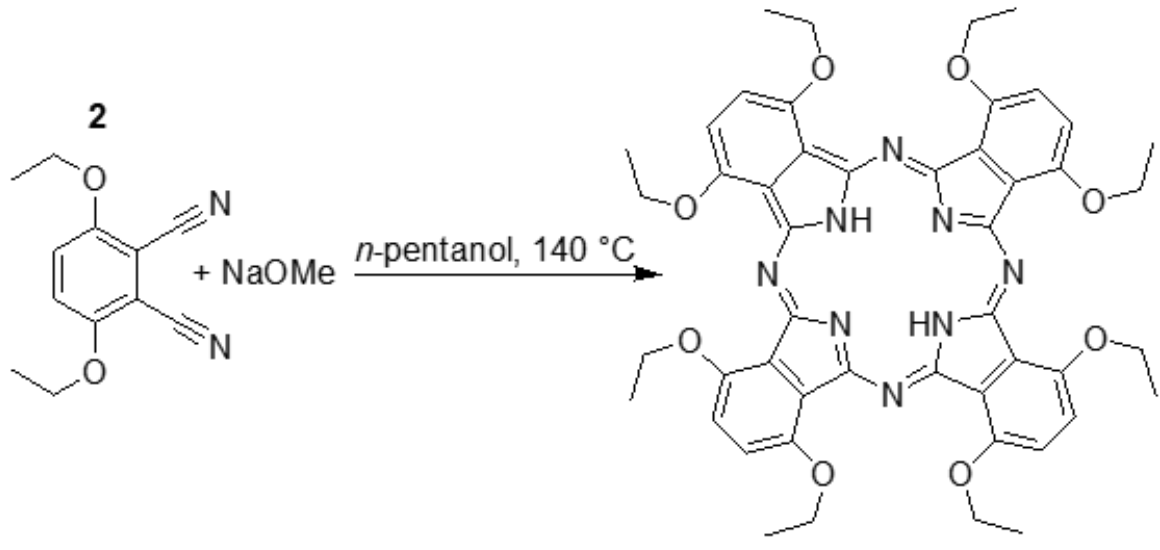

Scheme S-2. Preparation of 1,4 ,8, 11, 15, 18, 22, 25-octaethoxy-29H, $31 H$-phthalocyanine (3)

\section{Procedure}

A $16 \mathrm{~mL}$ scintillation vial was charged with $495 \mathrm{mg}(2.29 \mathrm{mmol}) 2 \mathrm{SS} 134,222 \mathrm{mg}(4.11 \mathrm{mmol})$ sodium methoxide, and a stir bar. The reaction vessel was purged with argon and $5 \mathrm{~mL}$ 1-pentanol was injected into the vessel. The reaction vessel was immersed in an oil bath set to $140^{\circ} \mathrm{C}$ and stirred. The mixture turned dark green when the oil temperature exceeded $110^{\circ} \mathrm{C}$. The mixture was refluxed 45 minutes and the resulting mixture was purple. The mixture was added to $100 \mathrm{~mL}$ hexanes, resulting in a brown solid that was collected via centrifugation. The solid was dissolved in dichloromethane and washed with water, resulting in the organic phase turning from purple to green. The organic phase was separated and the solvent was removed in vacuo. The crude product was purified by flushing through a silica plug, pretreated with $1 \%$ triethylamine in dichloromethane, using $4 \%$ ethanol in

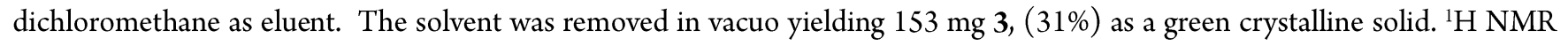
$\left(400 \mathrm{MHz}, \mathrm{CDCl}_{3}\right) \delta: 7.61(\mathrm{~s}, 8 \mathrm{H}), 4.95(\mathrm{q}, J=7 \mathrm{~Hz}, 16 \mathrm{H}), 1.83(\mathrm{t}, J=7 \mathrm{~Hz}, 24 \mathrm{H})$. 


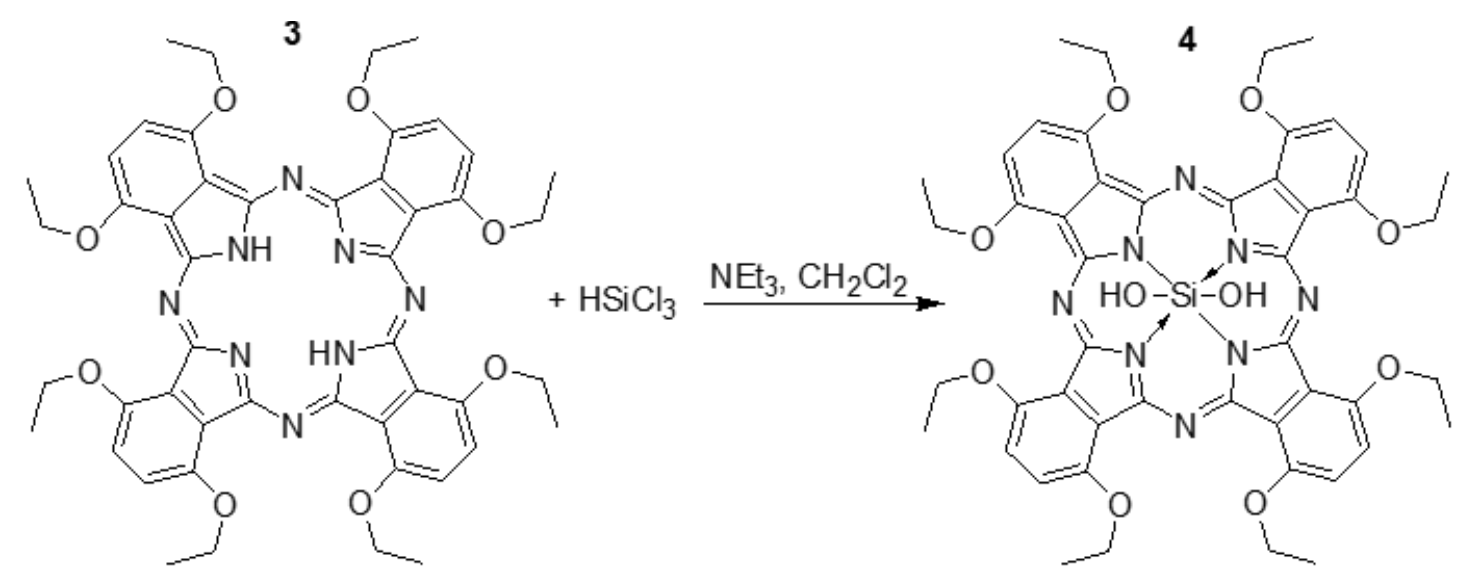

Scheme S-3. Preparation of silicon 1, 4, 8, 11, 15, 18, 22, 25-octaethoxy-phthalocyanine dihydroxide (4)

\section{Procedure:}

A $100 \mathrm{~mL}$ round bottom flask was charged with $150 \mathrm{mg}(0.173 \mathrm{mmol}) 3$, and a stir bar. $40 \mathrm{~mL}$ dichloromethane and $2.5 \mathrm{~mL}$ triethylamine (both dried overnight with molecular sieves) were injected into the reaction vessel. The solution was purged with argon $5 \mathrm{~min}$ while stirring. $0.5 \mathrm{~mL}(0.37 \mathrm{~g}, 5.0 \mathrm{mmol})$ trichlorosilane was added to the reaction mixture and the mixture was stirred overnight at room temperature. The solution was initially dark green and then turned maroon red. After overnight stirring, 1-2 $\mathrm{mL}$ water was slowly added to the mixture to quench the reaction. The solvents were removed in vacuo and the mixture was dispersed in $100 \mathrm{~mL}$ water. The mixture was stirred then centrifuged. The supernatant was decanted and the solid product was washed with water and centrifuged again. The supernatant was decanted and the residual water was removed in vacuo. The crude product was purified via flash chromatography (hand column) on silica using $10 \%$ ethanol in dichloromethane as eluent. The solvent was removed in vacuo yielding $86 \mathrm{mg}(54 \%) 4$ as green crystalline solid. UV/Vis (chloroform) $\lambda_{\max }=766 \mathrm{~nm}$ $(\log (\varepsilon)=5.22) .{ }^{1} \mathrm{H}$ NMR $\left(400 \mathrm{MHz}, \mathrm{CDCl}_{3}\right) \delta: 7.66(\mathrm{~s}, 8 \mathrm{H}), 4.97(\mathrm{q}, J=7 \mathrm{~Hz}, 16 \mathrm{H}), 1.81(\mathrm{t}, J=7 \mathrm{~Hz}, 24 \mathrm{H})$. 


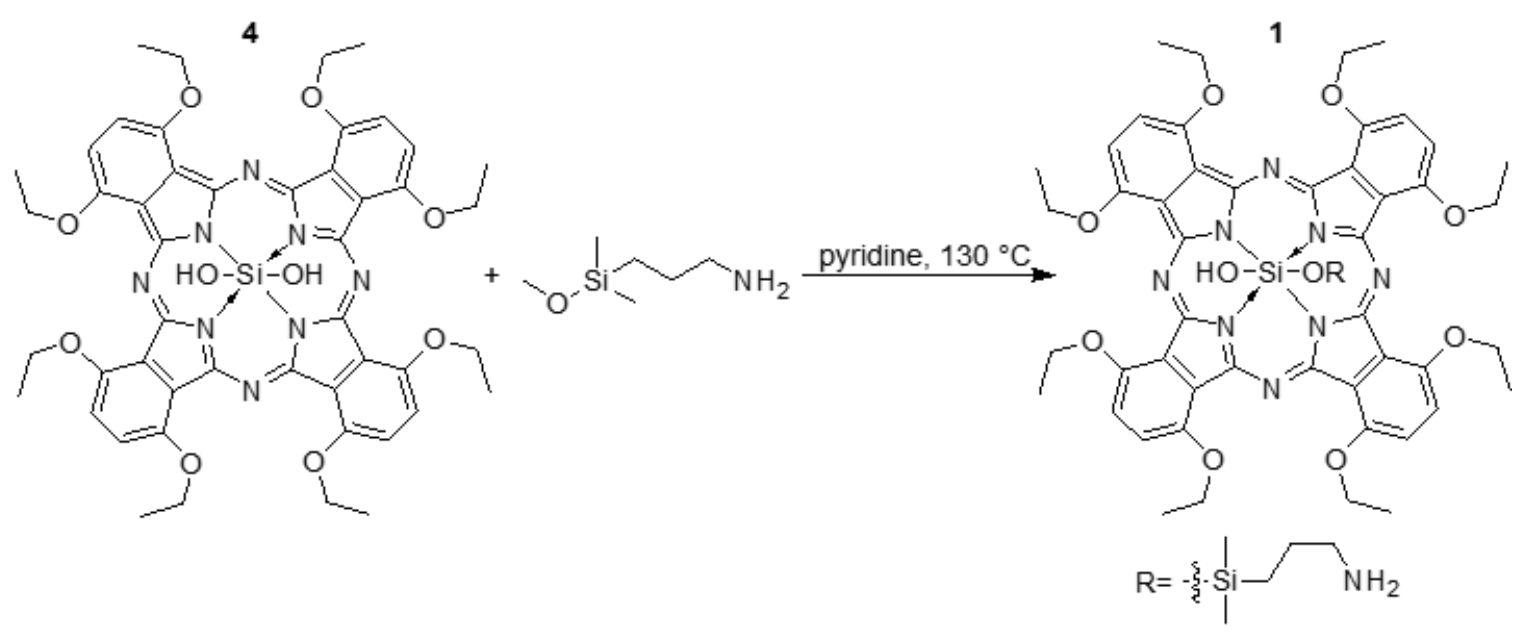

Scheme S-4. Preparation of silicon 1, 4, 8, 11, 15, 18, 22, 25-octaethoxy-phthalocyanine hydroxide Si, Si-dimethyl Si-(3'aminopropyl)siloxide (1)

\section{Procedure:}

A $50 \mathrm{~mL} 3$ neck flask was equipped with a short path distillation head and a $10 \mathrm{~mL}$ receiving flask. The reaction vessel was purged with argon and charged with a stir bar and $70 \mathrm{mg}(0.076 \mathrm{mmol}) 4.10 \mathrm{~mL}$ pyridine and $21 \mathrm{mg}(0.143 \mathrm{mmol})$ (3-aminopropyl)dimethylmethoxysilane. The reaction vessel was immersed in an oil bath set to $130^{\circ} \mathrm{C}$. Several milliliters of pyridine were distilled and the reaction mixture was cooled. The reaction mixture was combined with toluene (added to aid the removal of pyridine by azeotrope formation) and the solvents were removed in vacuo. The crude product was dissolved in dichloromethane immobilized on sand. The product was purified by chromatography using a $15.5 \mathrm{~g}$ amine-silica gold column (gradient elution, dichloromethane to $6 \%$ ethanol in dichloromethane). The solvents were removed in vacuo yielding $40 \mathrm{mg}(50 \%) \mathbf{1}$ as a green crystalline solid. ${ }^{1} \mathrm{H}$ NMR $\left(400 \mathrm{MHz}, \mathrm{CDCl}_{3}\right) \delta: 7.67(\mathrm{~s}, 8 \mathrm{H}), 4.97(\mathrm{q}, J=7 \mathrm{~Hz}, 16 \mathrm{H}), 1.76(\mathrm{t}, J=7 \mathrm{~Hz}, 24 \mathrm{H}), 0.89(\mathrm{~m}, 2 \mathrm{H}),-0.95$ $(\mathrm{m}, 2 \mathrm{H}),-2.13(\mathrm{~m}, 2 \mathrm{H}),-2.61(\mathrm{~s}, 6 \mathrm{H})$. 
${ }^{1}$ H NMR Spectra

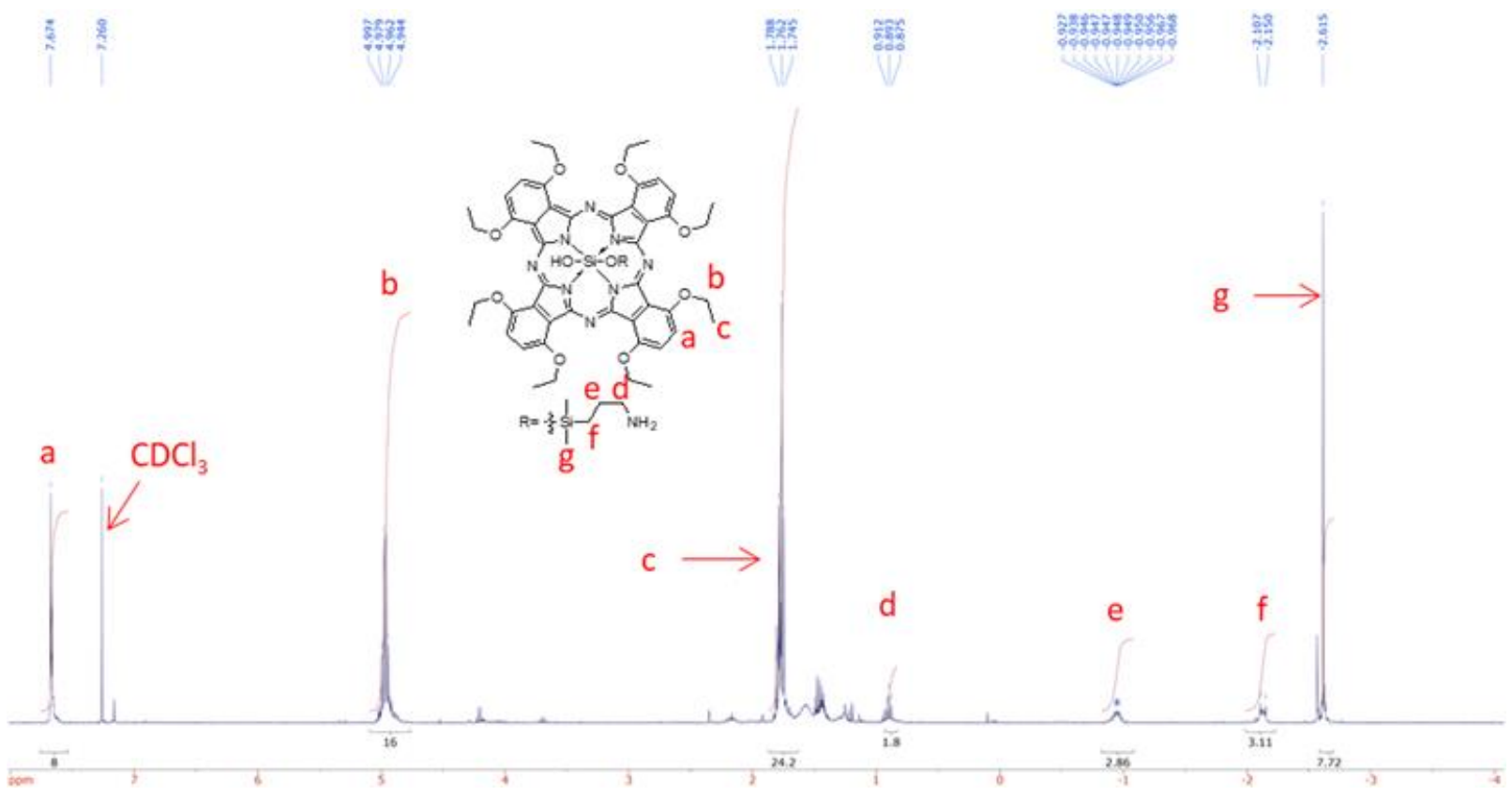

Compound 1. This spectrum was acquired using $\mathrm{CDCl}_{3}$ as solvent.
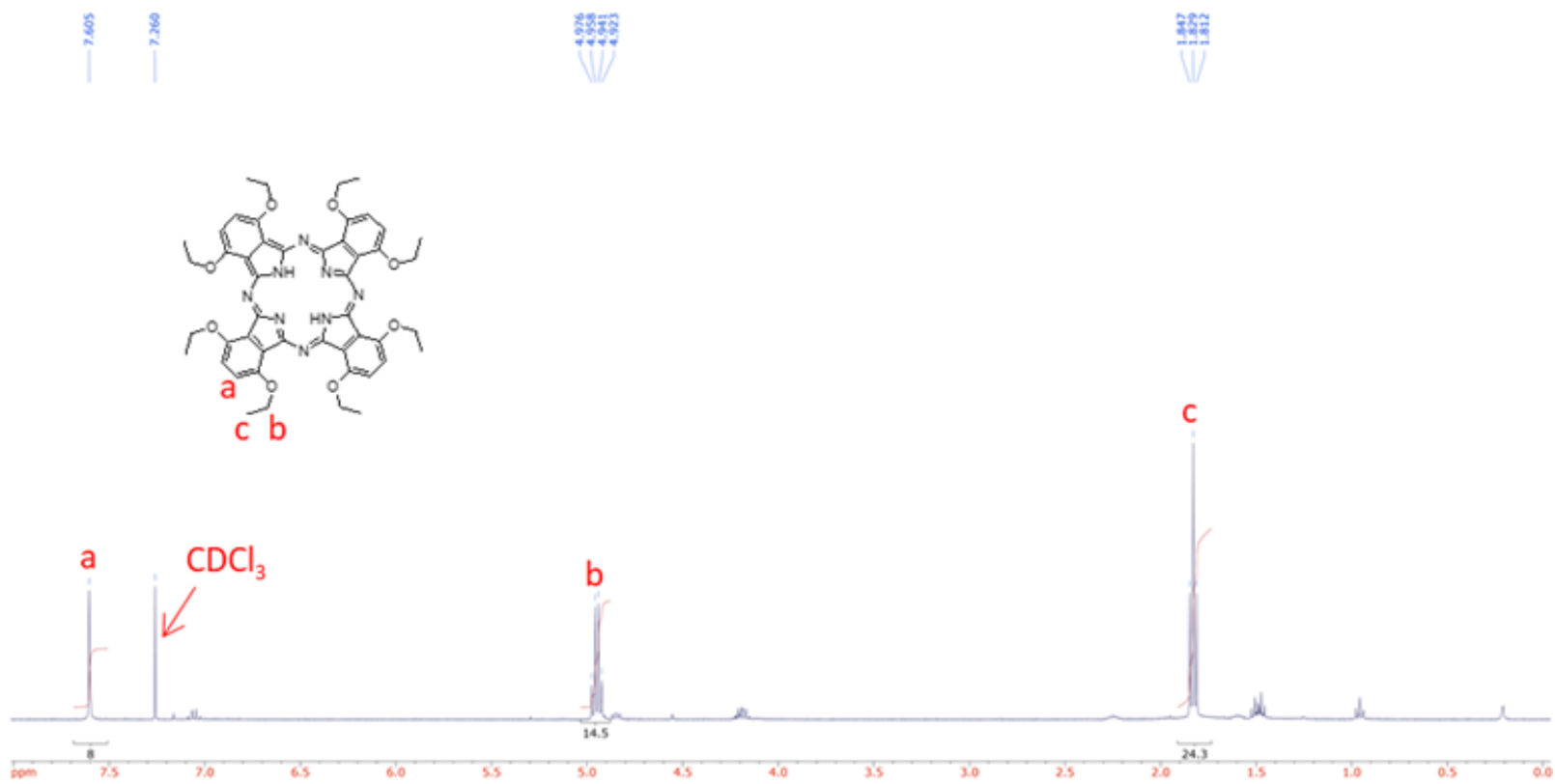

Compound 3. This spectrum was acquired using $\mathrm{CDCl}_{3}$ as solvent. 


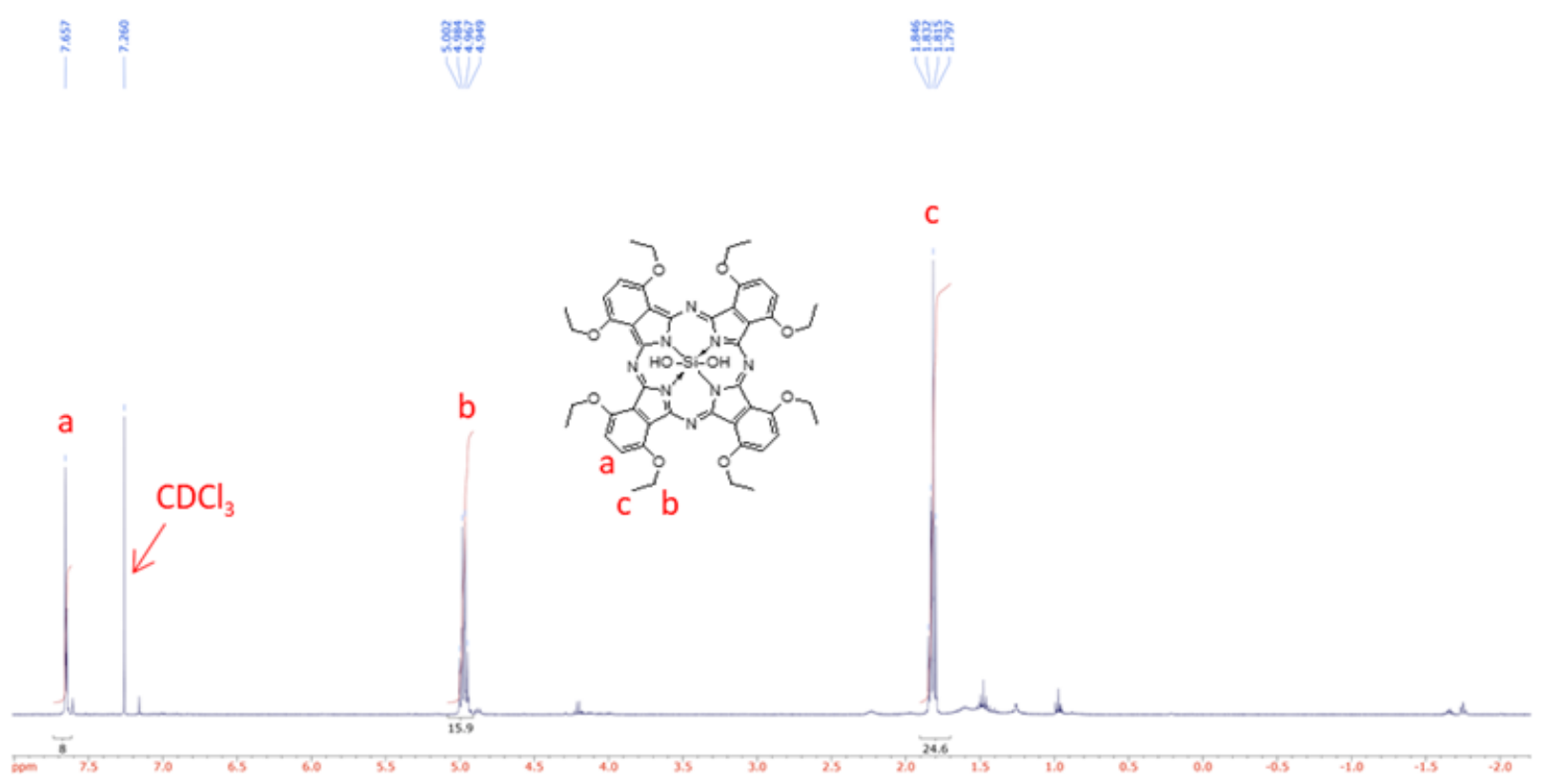

Compound 4. This spectrum was acquired using $\mathrm{CDCl}_{3}$ as solvent.

\section{REFERENCES}

1. Morales, J. M.; Skipwith, C. G.; Clark, H. A., Quadruplex Integrated DNA (QuID) Nanosensors for Monitoring Dopamine. Sensors 2015, 15 (8), $19912-19924$.

2. Lorenz, R.; Bernhart, S. H.; Honer Zu Siederdissen, C.; Tafer, H.; Flamm, C.; Stadler, P. F.; Hofacker, I. L., ViennaRNA Package 2.0. Algorithms Mol Biol 2011, 6, 26-40.

3. Munteanu, M. G.; Vlahovicek, K.; Parthasarathy, S.; Simon, I.; Pongor, S., Rod models of DNA: sequence-dependent anisotropic elastic modelling of local bending phenomena. Trends in biochemical sciences 1998, 23 (9), 341-347.

4. Parisien, M.; Major, F., The MC-Fold and MC-Sym pipeline infers RNA structure from sequence data. Nature 2008, 452 (7183), 51-5.

5. Humphrey, W.; Dalke, A.; Schulten, K., VMD: visual molecular dynamics. Journal of molecular graphics 1996, 14 (1), 33-38.

6. Shimada, J.; Maruyama, T.; Kitaoka, M.; Kamiya, N.; Goto, M., DNA-enzyme conjugate with a weak inhibitor that can specifically detect thrombin in a homogeneous medium. Analytical biochemistry 2011, 414 (1), 103-108.

7. Zhou, T.; Chen, P.; Niu, L.; Jin, J.; Liang, D. H.; Li, Z. B.; Yang, Z. Q.; Liu, D. S., pH-Responsive Size-Tunable Self-Assembled DNA Dendrimers. Angewandte Chemie-International Edition 2012, 51 (45), 11271-11274.

8. Bock, C.; Franz, S.; Zentgraf, H.; Sommerville, J., Electron Microscopy of Biomolecules. Encyclopedia of Molecular Cell Biology and Molecular Medicine. Wiley-VCH Verlag GmbH \& Co. KGaA: 2006, 106-109.

9. Würth, C.; Grabolle, M.; Pauli, J.; Spieles, M.; Resch-Genger, U., Relative and absolute determination of fluorescence quantum yields of transparent samples. Nature protocols 2013, 8 (8), 1535-1550.

10. JoVE Science Education Database. Analytical Chemistry: Method of Standard Addition. JoVE: Cambridge, MA, 2018, (https://www.jove.com/science-education/10201/method-of-standard-addition).

11. Borysiak, M. D.; Thompson, M. J.; Posner, J. D., Translating diagnostic assays from the laboratory to the clinic: analytical and clinical metrics for device development and evaluation. Lab on a Chip 2016, 16 (8), 1293-1313.

12. Frenette, M.; Hatamimoslehabadi, M.; Bellinger-Buckley, S.; Laoui, S.; La, J.; Bag, S.; Mallidi, S.; Hasan, T.; Bouma, B.; Yelleswarapu, C.; Rochford, J., Shining light on the dark side of imaging: excited state absorption enhancement of a bis-styryl BODIPY photoacoustic contrast agent. Journal of the American Chemical Society 2014, $136(45), 15853-15856$.

13. McCormick, K. P.; Willmann, M. R.; Meyers, B. C., Experimental design, preprocessing, normalization and differential expression analysis of small RNA sequencing experiments. Silence 2011, 2 (1), 2-24.

14. Martinelli, E.; Lüdke, A.; Adamo, P.; Strauch, M.; Di Natale, C.; Galizia, C. G., Normalizing brain activity across individuals using functional reference mapping. Scientific reports 2017, 7 (1), 17128-172137.

15. Russin, T.; Altinoğlu, E. İ.; Adair, J.; Eklund, P., Measuring the fluorescent quantum efficiency of indocyanine green encapsulated in nanocomposite particulates. Journal of Physics: Condensed Matter 2010, 22 (33), 334217-334227.

16. Cook, M. J.; Dunn, A. J.; Howe, S. D.; Thomson, A. J.; Harrison, K. J., Octa-alkoxy phthalocyanine and naphthalocyanine derivatives: dyes with Qband absorption in the far red or near infrared. Journal of the Chemical Society, Perkin Transactions 1 1988, (8), 2453-2458. 